DOI: $10.21278 /$ TOF.41208

ISSN 1333-1124

eISSN 1849-1391

\title{
SHARED RESPONSIBILITY FOR A CLEAR AND ACCESSIBLY WRITTEN SCIENTIFIC PAPER
}

\begin{abstract}
In this paper, a hypothesis of shared responsibility for a clear and accessibly written scientific paper published in a scientific journal is put forward and discussed. Among the parties sharing the responsibility, i.e. the author, the peer reviewer, the editor-in-chief together with the editorial board, and the language editor, the author has the greatest responsibility. Producing a clear and reader-friendly text to present a scientific content in a proper way is not an easy task for the author. The purpose of this paper is, therefore, to highlight some important issues related to scientific writing, such as the structure of the paper, precision and clarity of the text, terminology, abbreviations, and spelling. The challenges of academic writing are illustrated by characteristic examples taken from the papers published in the Transactions of FAMENA. Some experience-based tips on how to develop academic writing skills and recommendations for improving the quality of the text are given in conclusion.
\end{abstract}

Key words: $\quad$ a clear and reader-friendly text, shared responsibility, academic writing skills

\section{INTRODUCTION}

An excellently written and extremely useful editorial entitled "Elements of style" published in Nature Physics [1] came as a revelation to me when I first read it because it puts forward the idea of clear and accessibly written scientific papers. Based on my experience as a language editor of the papers published in the Transactions of FAMENA (FAMENA Faculty of Mechanical Engineering and Naval Architecture), I have also come to a conclusion that scientific research results, technological breakthroughs, and ingenious solutions to acute problems do deserve to be presented in a well written text. Moreover, I dare say that a clear and accessibly written research paper makes the reader fully appreciate the scientific content presented in the paper. The editorial "Elements of style" has motivated me to write about my idea of the shared responsibility in the writing and editing of scientific papers. In addition, it has supported my belief that a non-specialist reader should be able to understand the "story" of the paper. That is the reason why this paper is a narrative. The story of this paper is dedicated to the authors and readers of the Transactions of FAMENA in an attempt to help in the hard process of writing and to share some ideas about how to make it more efficient.

Writing is a creative process, so is the writing of scientific papers. There is a widespread assumption that the authors of scientific papers should follow a strict set of rules in the process of writing. This is surely true when the structure of the paper is concerned. As for the scientific content, it can be fully appreciated only if it is presented in a carefully written text. That is why 
the second section of this paper is dedicated to scientific writing with special reference to how to make the text clear and easy to follow even to a reader who is not an expert in the field.

The third section deals with the hypothesis of shared responsibility for a reader-friendly scientific paper published in a scientific journal. The responsibility is laid on the author in the first place, but also on the peer reviewer, the editor and the editorial board, and on the language editor. As this paper is written with a focus on the text, the very important nonverbal information in the form of tables, graphs, and diagrams is not dealt with here.

The author of a scientific paper has a direct responsibility for producing a clear and accessibly written text. It is only natural since he/she is the one who should care most. Unfortunately, the author sometimes lacks the knowledge and/or skills required for communicating scientific information effectively and sometimes he/she does not pay full attention to the text. Fortunately, the skill improves with writing. Therefore, suggestions as how to avoid some mistakes and how to improve the quality of the text might come in handy.

In order to be published, scientific papers have to be peer-reviewed to have their suitability for publication determined. It is not my place to discuss either the issues related to the scientific content review or the reviewer's responsibility with respect to that, but I would like to point out the reviewer's responsibility for the terminology and for constructive and practical suggestions about improving the language of the paper. In addition to that, I think that the reviewer should also take the role of a technical editor.

The editor's and the editorial board's responsibility primarily rests with selecting papers with excellent scientific content, which goes without saying. Here, I would like to point out their responsibility for taking care of maintaining the high level of quality not only of the scientific content but also of the way it is presented. This is what the editor-in-chief and the editorial board do and should be given credit for.

The language editor is responsible for checking the quality of the text in terms of accuracy and structure and for improving it where possible without interfering with the scientific content. As the language editor's scope of expertise is the text, he/she should always be aware of his limitations regarding the scientific content and should only suggest changes that are to be verified and then accepted or rejected by the author. In addition, a good language editor should have the basic knowledge of the scientific fields he/she deals with. This knowledge is required both for understanding the text from the linguistic point of view and for being a critical reader from the point of view of good scientific writing. Different aspects of language editor's work are discussed on the basis of practical experience.

Finally, in the fourth section, some conclusions regarding the responsibility for a clear and accessibly written text are drawn and a list of suggestions for good scientific writing is given, hopefully to the benefit of the reader/prospective author.

\section{SCIENTIFIC WRITING}

In this section, I discuss the aspects of scientific writing that I have come across in my work and that have proven to pose problems. Some of these aspects are illustrated with reallife examples from the texts published in the Transactions of FAMENA. The general structure of a scientific paper is usually not a problem, but the functions to be fulfilled by each section are sometimes neglected. In the introduction to his book, Alley [2] lists the elements which make the scientific writing difficult. I find the inherent complexity of both the subject and the language, including the specific terms, the most relevant among them. Nothing can be done about the complexity of the subject, but the complexity of the language should be controlled in order to produce strong scientific writing. Some answers to the question how to do it are given in the sub-sections below.

\subsection{Structure of a scientific paper}

A scientific paper may be divided into three main parts, the beginning, the middle, and the ending. As simple as that! But each section of the paper has its particular function as shown in Table 1 (based on [2-6]). 
Table 1 Basic structure of a scientific paper and the functions to be fulfilled by each section

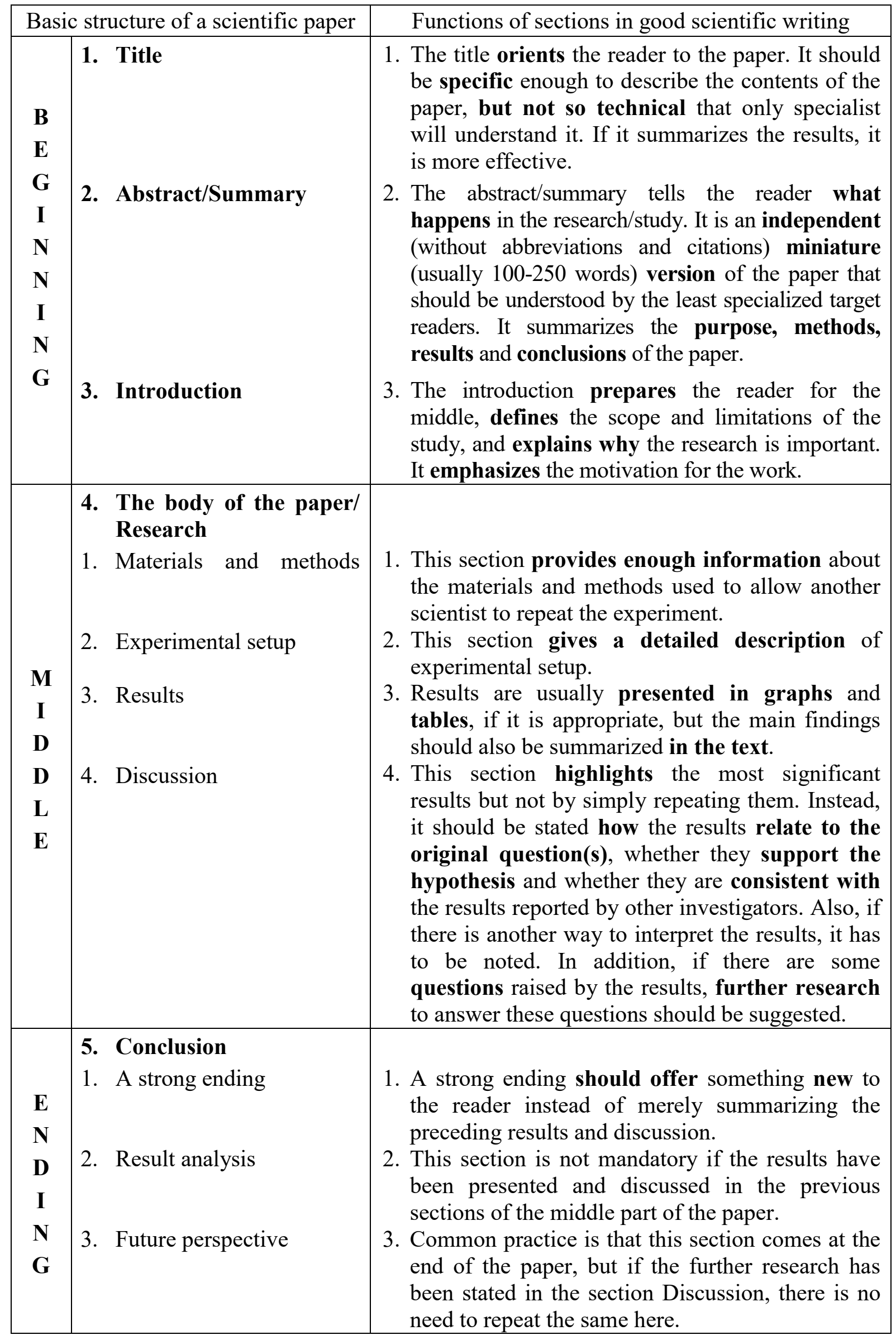


Obviously, it is not the very structure that may pose a problem, but the functions of each section that have to be fulfilled in good scientific writing. For example, some authors tend to repeat in the conclusion the sentences from the section dealing with the research results or those used in the discussion of the results. This common practice has its benefits in highlighting the important achievements of the research, but it does not contribute to the quality of the text, nor does it capture the reader's attention throughout the paper. At its extreme, this tendency of repeating the same sentences in different sections of the text may result in poor scientific writing that is not suitable for publication.

\subsection{Characteristics of good scientific writing}

As I keep using the term good scientific writing, it is about time to define it. I like Bednar's simple definition of scientific writing as formal writing with strict rules which are often unstated. Formal writing needs to be clear, unambiguous, literal, and well-structured [3]. Clearly, such a result can come only from good thinking and a lot of effort spent on writing and rewriting.

My list of the most important characteristics of good scientific writing is based on the literature on the topic [2-6], but the selection of the particular characteristics expresses my view on the topic based on the experience as a language editor in the Transactions of FAMENA. Thus, I have put "precision and clarity of the text" on the top of the list, followed by "terminology" because I think that good scientific writing implies a good text in the first place, and then the use of the precise field-related terminology [7]. This approach also puts the reader in the focus, a tendency that has been around for some time [4, 5]. High-quality scientific papers are interesting and useful to many readers, including newcomers to the field, and not only to a small set of highly specialised readers [5].

\subsubsection{Precision and clarity of the text}

The complexity of the subject dealt with in the scientific paper requires precision on the one hand and clarity on the other. Precision and clarity of the text depend on:

- a well-structured sentence as the basic unit of the text,

- the way how sentences are integrated into a larger unit, the text.

In scientific writing, a well-structured sentence containing appropriate words is in service of communicating a new piece of information. On the other hand, this sentence has to fit in with the context to build a meaningful text. Thus, in any sentence, some elements express, or refer back to the information that is familiar from the preceding sentence(s)/text, i.e. the given information, while others present new information. The best distribution of the given and the new information contributes to a gradual rise in information load [8].

\subsubsection{Sentence structure}

In scientific writing where stylistic effects may interfere with the communicative needs, a well-structured sentence is usually the one following the regular subject-verb-object word order [8], e.g. Typical examples of panel-like structures include high-speed trains, automobiles, ship hulls, etc. (original sentence from a paper). Such a sentence may seem to be too simple, but it surely does not misdirect reader as it may be the case with complex sentences such as the following one:

Example 1:

Small cylindrical parts made of advanced conductive materials, which are difficult to machine by a conventional cutting methods such as milling and turning, can be produced by EDM machine, so there is a great potential for improving EDM to afford manufacturing such type of components by setting up an external rotary axis on conventional EDM and feeding tool electrode against rotary workpiece in order to produce axisymmetrical geometries. (68 words) 
Although this sentence has grammar and spelling mistakes which must be corrected and probably some terminology issues to be dealt with (e.g. setting up an external rotary axis), a non-expert reader can identify the following thoughts:

1. It is difficult to machine small cylindrical parts using conventional cutting methods.

2. Small cylindrical parts are made of advanced conductive materials.

3. Milling and turning are conventional cutting methods.

4. An electrical discharge machine (EDM) can produce small cylindrical parts made of advanced conductive materials.

5. To produce such parts, a conventional EDM has to be improved.

6. The improvement includes a) setting up an external rotary axis on a conventional EDM, and b) feeding the tool electrode against rotary workpiece.

7. By this improvement, axisymmetric geometries are obtained.

There are definitely too many things to be followed in one sentence and they surely misdirect the reader. Furthermore, there is an internal contradiction between statement 4 and statement 5 because the former states that an EDM can produce small cylindrical parts and the latter that a conventional EDM has to be improved for that purpose (statement 5). Clearly, the sentence has to be divided into at least two separate sentences, one stating the problem (difficulties in machining small cylindrical parts using conventional cutting methods, such as milling and turning) and the other stating the solution (an EDM improved by a and $b$ from statement 5). I have proposed a solution containing three sentences:

Small cylindrical parts made of advanced conductive materials are difficult to machine by a conventional cutting methods, such as milling and turning. (22 words) Such components can be produced by an improved conventional electrical discharge machine (EDM). (13 words) The improvements consist of setting up an external rotary axis on the conventional EDM and of feeding the tool electrode against the rotary workpiece in order to produce axisymmetric geometries. (30 words)

Complex sentences put an extra burden on the reader in terms of more than one thought to be followed and in terms of too many words in a sentence. In proposing a solution to the problem of the analysed complex sentence, I have followed a simple rule of "one thought, one sentence" which results in sentences that are not too long. Thus, the three sentences which present a problem, its solution, and the way the solution is realized, respectively, have three words less than the original sentence (65:68). Sentences of up to 40 words are generally considered to be of an appropriate length.

The choice of words, as building elements of a sentence, is very important. Experts on scientific writing agree that definite, specific, concrete language should be used [6] as complex wording buries ideas. Bednar [3] and Sage [9] advocate clear texts that are comprehensible to as many people as possible. This is in contradiction with a culture of being intentionally obscure when presenting a complex scientific subject. I strongly support simple, but precise wording in presenting complex subjects. This does not mean that simplicity may involve inaccuracy or the lack of precision. Let me explain what I mean by the following examples:

\section{Example 2:}

Hybrid joints have also been used for the repair and improvement of damage tolerance.

The original sentence has a good structure and no grammar mistakes. The choice of words, however, is inappropriate because "damage tolerance", by definition, cannot be "repaired", it can only be "improved". Therefore, I have suggested the omission of the highlighted two words. This satisfies the requirement of precise wording.

The sentence given below is a good example of too complicated wording: 
Example 3:

Application of chemical coagulants to generate a fine flocks to aid removal efficiency of suspended solids before membrane filtration is often used within wastewater treatment.

This sentence has one grammar mistake (a fine flocks - indefinite article used in front of a noun in plural), but the mistake does not disturb the understanding of the sentence. On the other hand, too many complicated and inappropriate phrases (application of.....is used, to aid removal efficiency of suspended solids, within wastewater treatment) put an extra load on the reader. To make this sentence more reader-friendly, I have suggested the following changes:

In the wastewater treatment process, Application of chemical coagulants are often used before membrane filtration to create generate a fine flocks which help in the to aid-removal efficiency of suspended solids-before membrane filtration is often used within wastewater trent.

In the wastewater treatment process, chemical coagulants are often used before membrane filtration to create fine flocks which help in the removal of suspended solids.

The proposed sentence has the same number of words, but the grammar mistake is corrected and the expression "to aid removal efficiency of suspended solids", which could be misinterpreted as "to improve the efficiency of suspended solids in removing something", is changed. Omitting the unnecessary words and adding some meaningful words result in a clearer sentence with a better distribution of the information load.

According to the Principles of Composition (no. 22) [6], the word or group of words that the writer desires to make most prominent is usually the end. I have chosen a sentence in which this rule has not been obeyed as the verb is placed at the end of the sentence.

\section{Example 4:}

By specifying wave characteristics of one of the wave theories on the fixed inflow boundary the wavemaker is provided.

The new information to be communicated by this sentence is how the wavemaker is provided. Putting this new information at the beginning of the sentence creates imbalance. A simple change consisting of putting the subject at the beginning creates balance and puts the most prominent piece of information at the end of the sentence.

The wavemaker is provided Bby specifying wave characteristics of one of the wave theories on the fixed inflow boundary the wemaker is provided.

The wavemaker is provided by specifying wave characteristics of one of the wave theories on the fixed inflow boundary.

Please note that I have not dealt with the meaning, only with the structure. Thus, any remarks and questions about the meaning of single words and groups of words should be addressed to the author of the sentence.

In a well-structured sentence, the related things are kept as close as possible. This facilitates the reading and understanding of the text [6].

Example 5:

Mohammadi et al. [10] investigated the effect of machining parameters on surface finish and roundness in wire electrical discharge turning (WEDT) of cemented steel using statistical analysis.

The related things I have in mind here are highlighted. The researchers used "statistical analysis" to "investigate the effect of...". In the original sentence these two related parts of the sentence are distant from each other, while they are much closer in the rephrased one: 
Using statistical analysis, Mohammadi et al. [10] investigated the effect of machining parameters on the surface finish and roundness of cemented steel in wire electrical discharge turning (WEDT).

The principle of parallel construction [6] requires that expressions similar in content and function be outwardly similar. This certainly helps the reader grasp the meaning more easily.

Example 6:

The above optimal problem can be categorized as a unimodal function and the golden section search method can be used to solve such problem [15].

This sentence can be easily understood by the expert reader although its structure does not adhere to the principle of parallel construction. In spite of the fact that both clauses of the sentence are about the same thing, i.e. "a problem" (underlined), they have different subjects (highlighted). My suggestion is to adhere to the principle of parallel construction and to produce a sentence which requires less effort on the part of the reader. In addition to the change in the sentence structure, a minor mistake should be corrected, i.e. the inappropriate collocation optimal problem. If you have a problem, then it can be described by a number of adjectives but the adjective "optimal" (best or most favourable; optimum) is definitely not among them because of the meaning of the word "problem" (difficulty). There is a term "optimization problem" (the problem of finding the best solution from all feasible solutions). Whether this is the case here the language editor is not entitled to decide without the approval from the author. Thus, the proposed final version of the sentence is:

The above optimal problem can be categorized as a unimodal function; such a problem and the golden section search method-can be used to-solved using the golden search method such problem [15].

The above problem can be categorized as a unimodal function; such a problem can be solved using the golden section search method [15].

To conclude this section, I must admit that a number of important things about the sentence structure have not been discussed due to the nature of this paper. Yet, I hope that the problem of sentence structure has been properly addressed by the provided examples to give the reader an insight into it.

\subsubsection{Integrating sentences into a paragraph/text}

A group of well-structured sentences about a single topic form a paragraph. The sentences within a paragraph should be properly connected in order to create a smooth flow of ideas. Means used for that purpose are cohesive devices, i.e. words and phrases that connect sentences and paragraphs together into a united whole [10]. Halliday and Hasan identified five categories of cohesive devices that create coherence in a text, i.e. reference, substitution, ellipsis, conjunction, and lexical cohesion [11].

In the same way, a group of related paragraphs form a text (defined in Cambridge Grammar of English as ,a stretch of language, either in speech or in writing that is semantically and pragmatically coherent in its real-world context" [12]). When a text is semantically and pragmatically coherent, it means that it is logical, well organized, easy to understand, and clear; consequently, the reader can understand the main points of the text without any problems.

The purpose of the examples provided below is to show only some possibilities of how to link sentences properly to contribute to the meaningfulness of the text. Thus, I will 
illustrate four of the five categories of cohesive devices, i.e. reference, substitution, conjunction, and lexical cohesion. The aim is for the reader to get just a general idea about the issue of integrating sentences into a text.

The first example refers to linking words or connecting words, which incorporate conjunctions and transitions. Conjunctions are used within a sentence, while transitions are used to connect sentences together or relate ideas to one another.

Example 7:

Finally, signal-to-noise $(S / N)$ ratio analysis was conducted to find the optimal settings and factor levels. Subsequently, optimal process parameters were verified by three experiments.

These two sentences refer to two different stages in a process which are introduced by the right transition words expressing chronology. The problem is that "Finally" precedes "Subsequently", which is in direct contradiction to their meanings. If you use "Finally", then you cannot have another sentence beginning with "Subsequently". There is nothing after "Finally". Hence, the corrected text has "subsequently" as a transition word in the first sentence, and "finally" in the second:

Subsequently, signal-to-noise $(S / N)$ ratio analysis was conducted to find the optimal settings and factor levels. Finally, optimal process parameters were verified by three experiments.

Example 8:

Results show that salt bath nitrocarburizing, as well as plasma nitriding at low temperature, increased microhardness without reducing corrosion resistance. Instead, the pitting corrosion resistance of X17CrNi16-2 was improved.

This is another example of starting a sentence with an inappropriate transition word. The transition word "instead" expresses contrast, and what we need here is a transition word expressing additional information. Therefore, the relation between the first and the second sentence is not clear and, as a result, the two-sentence text is not coherent. When "Moreover" is used instead, the meaning becomes clear and, consequently, the text becomes coherent:

Results show that salt bath nitrocarburizing, as well as plasma nitriding at low temperature, increased microhardness without reducing corrosion resistance. Moreover, the pitting corrosion resistance of X17CrNi16-2 was improved.

Example 9:

During the irradiation with $U V-A(365 \mathrm{~nm})$, no degradation of PZQ was observed. The $U V-A$ radiation did not provide enough energy to degrade the complex organic substance such as PZQ. Whereas, when the solution of PZQ was submitted to the photolysis with the predominant wavelengths of 185/254 $\mathrm{nm}(U V-C)$ it was degraded after $15 \mathrm{~min}$. The $U V-C$ radiation gives higher energy level and therefore is adequate for degradation of complex molecules such as $\mathbf{P Z Q}$ in this case.

Using the example of this four-sentence text, I can explain why the text cannot be considered as completely coherent, although, I must admit that an expert reader can understand it without any difficulties due to his expert knowledge shared with the author of the considered text. Yet, an expert reader might have some questions about the specific fieldrelated terminology, i.e. about the meaning of " $185 / 254 \mathrm{~nm}$ " and the doubtful collocation "submit to photolysis". However, terminology issues will not be discussed here as the focus is on the coherence and cohesion.

The underlined words in the second sentence are examples of reference. The first underlined group of words is "the solution of PZQ" and the second is the pronoun "it" which 
refers back either to "the solution of PZQ" or to "PZQ". Obviously, based on the expert knowledge about photolysis (photolysis - chemical decomposition by the action of radiant energy (as light) [13]) and in accordance with the main topic of the paper, the pronoun replaces PZQ. Since there is a possibility of misinterpretation, it is better to use "PZQ" instead of "it". In this way, the established lexical cohesion in the form of repetition, used instead of reference, clears up any possible doubts.

In the third sentence, the transition word "such as" introduces an example of "complex molecules". The problem is that "PZQ", a substance, is offered as the example instead of "molecules of PZQ". In order to avoid the repetition of the word "molecules", I have replaced it with a pronoun "those". Thus, the final version is "the degradation of complex molecules such as those of PZQ". This change is an example of the cohesive device of substitution because the demonstrative pronoun "those" has been substituted for "molecules".

Finally, the highlighted conjunction "Whereas" used at the beginning of the sentence is a bad choice because it cannot be used at the beginning of the sentence in the role of a transition word. Instead, this conjunction links words, phrases, or clauses within a particular sentence to express the relationship of contrast. There are two transitional phrases that may express the same relationship between sentences: in contrast and on the other hand. I have opted for on the other hand.

Based on the above discussion, I have suggested the following version of the text. Please note that this is not the final version of the text as the terminology problems mentioned above have not been dealt with.

During the irradiation with $U V-A(365 \mathrm{~nm})$, no degradation of PZQ was observed. The $U V-A$ radiation did not provide enough energy to degrade the complex organic substance such as PZQ. On the other hand, when the solution of PZQ was submitted to the photolysis with predominant wavelengths of $185 / 254 \mathrm{~nm}(U V-C), P Z Q$ was degraded in $15 \mathrm{~min}$. The $U V-C$ radiation gives a higher energy level; therefore, it is suitable for the degradation of complex molecules such as those of $\underline{P Z Q}$.

\subsubsection{Terminology}

The terminology related to a specific field of research presented in a paper is very important for the expert reader, but it is usually not fully/or not at all understood by the nonexpert reader. However, if the terminology is incorporated in the text in a proper way, it does not hinder the general understanding of the text.

As a language editor, I have noticed a problem of creating new terminology in some countries. The newly-created terminology is different from the standard terminology in English but it is disseminated in the local community and can be found online. Thus, a paper with a title including the term "special technique parts" has been sent to the Transactions of FAMENA to be published. Without a context, one would hardly guess what it is all about. Since the paper deals with the problems of military equipment and vehicles, I suppose that the author used a literal translation of the term from his mother tongue (a Slavic language) since one of the meanings of the Croatian term "tehnika" is "mehanizacija", which would express the required meaning. A similar example is the term "paintwork material" coined and widely used in advertisements in some European countries. What is meant by the term is simply "paint" or "coating material". The difference between the two newly-created terms is that the term "special technique parts" is not transparent without a context, while "paintwork material" can be understood but still it is not a correct term. The fact that English has become a global lingua franca, "a language that people use to communicate when they have different first languages" [14], arouses mixed feelings. On the one hand, English plays a major role in 
the storage and dissemination of information in the world of science and technology [15], but also contributes to the storage and dissemination of wrong terminology, on the other.

Another, terminology-related problem is the problem of one concept communicated by different terms. The case may be that all the terms are good, but different terms for the same concept create confusion. Such a problem usually occurs in papers written by multiple authors. Thus, in a paper related to a ship, four different words, berth, quay, jetty, and pier, were used for the same concept, i.e. the fixed object to which a ship is attached with a rope. Each of the four authors used his own term and none of them paid attention to the problem of uniform style and consistent use of terminology. Moreover, the four terms which are used here are not synonyms, but near-synonyms [16], and they refer to a particular ship moored in a particular harbour. Therefore, the authors should have checked whether the ship was tied up in a harbour with a berth (a place for a ship to be tied up in a harbour [17]), a quay (a stone or metal platform in a harbour where boats come in to load[17]), a jetty (a wall or wooden platform built out into the sea, a river, etc., to which boats can be tied [17]), or a pier (a low structure of wood or iron built from the land out into the sea or a lake, where boats can stop and load/unload passengers or goods [17]). Clearly, the authors could have used either "berth" as a general term for the above mentioned concept, or only one of the three remaining terms which show differences in their meanings.

To conclude, I think it is the author's responsibility to know the proper English terminology used in his field of expertise, regardless of his level of proficiency in English, if he/she intends to publish papers in English.

\subsubsection{Abbreviations - initialisms and acronyms}

It is common knowledge that abbreviations, i.e. acronyms defined as "abbreviations formed from the initial letters of other words and pronounced as words (e.g. ASCII, NATO)" [18] and initialisms defined as "abbreviations consisting of initial letters pronounced separately (e.g. BBC)" [18], are commonly used in scientific texts. Sometimes, it seems to me, that they are over-used. Let me quote an author who dedicated her book to "all the CALS MA TEFL students who have participated in the ESP option". I bet you have no idea who those students were. Of course, experts in the field of teaching English as a foreign language (TEFL) are familiar with the third abbreviation, but the first two may be a problem even for them. The truth is that abbreviations, especially those less widely used or newly-coined ones may distract the reader's attention if they are not properly presented and if there are too many of them.

A properly presented abbreviation is the one which is written in brackets after its full form has been introduced, e.g. English for Specific Purposes (ESP). In scientific papers it is very important to do so because sometimes an acronym or an initialism may stand for different groups of words in different fields. Even the widely used initialisms, such as CNC, which is almost automatically interpreted as Computer Numerical Control, have to follow the rule stated above because they may represent different groups of words expressing various notions. CNC represents 74 different groups of words, among which there are 12 groups related to computers, e.g. Complex Number Calculator, Communications Network Control, Computer Numeric Code, Central Navigation Computer, Centralized Network Configuration, and Central Numerical Control. My point is that the author should not rely on the assumption of common knowledge in a particular context because the information in the scientific discourse should be precise and clear.

An example of improperly presented initialisms from a paper published in the Transactions of FAMENA in the period stated above are the initialisms KFSBC and DFSBC 
which stand for Kinematic Free-Surface Boundary Condition and Dynamic Free-Surface Boundary Condition, respectively [18]. These initialisms were used in the following sentence:

Example 10:

There are two fully nonlinear boundary conditions, the kinematic (KFSBC) and the dynamic boundary condition ( $\underline{D} F S \underline{B C}$ ) on the free surface $\left(S_{f}\right)$, as defined below.

This sentence should be rewritten in order to properly introduce the initialisms quoted above:

There are two fully nonlinear boundary conditions on the free surface $\left(S_{f}\right)$ : the kinematic free-surface boundary condition ( $\underline{K F S B C)}$ ) and the dynamic free-surface boundary condition (DFSBC), as defined below.

Thus, both initialisms are introduced properly, with all of its elements, which is not the case in the original sentence.

The other example related to initialisms can speak in favour of avoiding both the overuse of initialisms and the creation of tailor-made initialisms just for the purpose of a particular paper/study. A paper that I have recently edited contains sixteen different initialisms, out of which twelve are initialisms completely or partially created for the purpose of the paper. Consequently, the paper is read with difficulty and the reader's attention is diverted from the content to the form.

The tailor-made initialisms also interfere with the ease of following the "story" of the text. Some authors create their own initialisms in a particular paper because they probably want to economize with the number of words or to make the presentation of data in tables or graphs easier, but this attitude surely does not contribute to the ease of reading and understanding the text. To prove my point I can give the example of tailor-made initialisms which pose problems even to the authors of the text. Thus, one of the sixteen initialisms used in the text quoted in the previous paragraph, e.g. HFCM (hollow fibre C-membrane) is sometimes misspelled as HFMC, which proves that the real meaning of the initialism is lost. In addition, the authors take the use of initialisms to the extreme by replacing past participles by initialisms; thus, the initialism BW standing for "backwashing/backwash" is used in the passive structure "the membrane was BW", which should be avoided. Also, the initialism PT is proposed for the past participle "pre-treated" which is in contradiction with the rule that past participles cannot be replaced by initialisms when they are used to form a tense. Moreover, the use of initialism instead of a past participle cannot be accounted for by any relevant facts.

\subsubsection{Spelling}

In his script The Fight for English - 1 [19], David Crystal, a leading authority on the English language, says that "... there is a very close association between a standard language and writing" because "If a country is to have a standard language,... writing is the best medium for introducing it." It is quite clear that spelling, as "the defining feature of the standard variety of a language" is very important both for both the native speakers of English and the non-native ones.

Naturally, scientific papers require a standard language and authors cannot afford incorrect spelling as they can be considered "careless, lazy, or uneducated, or possibly all three" [19]. Therefore, extra precaution should be taken to avoid spelling mistakes. But, unfortunately, mistakes of the lapsus calami type do occur and not much can be done about that. The spelling check tool cannot spot the mistake if the mistake has resulted in a word that exists in English and neither can the author because he/she reads what he/she expects in the context and not what is actually written. For example, in a paper dealing with gears, if you come across the term "peach diameter", the spelling mistake can either pass unnoticed or it 
can make you laugh, but still, you know that this is the "pitch diameter" that we deal with in the context.

Another problem related to spelling is a superficial knowledge of words. Thus, words with slight differences in spelling may be used in a wrong way. If the author does not know the right spelling of the word he/she needs in a context and does not check it with the dictionary, then we can have the word "interference" used instead of "interface" in the expression "coating substrate interference". The meaning that the author wanted to convey was "the interface between the coating and the substrate", so the right term is "coating/substrate interface". The same author states that "extensive measurements are required to improve the durability of all systems and materials", while what he means are "extensive measures".

As far as the American or the British English spelling are concerned, authors are generally free to use the one they prefer, but it is very important to maintain the consistency in the chosen spelling. For example, if your preferable spelling is the American one, then you should use color and aluminum throughout the text and not both color and colour or aluminum and aluminium. Sometimes, publishers may require the use of only one spelling (in the Transactions of FAMENA we kindly ask authors to use the British English spelling), but the texts using the other spelling are accepted and the spelling is changed by the publisher.

Authors should make a special effort to spell names correctly as an author's last name is like the key in a database lookup [20]. If an author's last name in References is misspelt, the reader will not be able to locate the works by that author. I think that Kohl [20] is right when he states that the misspelt last name means that not enough attention has been paid to the author and his work.

\section{SHARED RESPONSIBILITY FOR A PUBLISHED SCIENTIFIC PAPER}

The author is not the only one who is responsible for the quality of the published scientific paper. The editor-in-chief and the editorial board, the peer-reviewer, and the language reviewer also have their share of responsibility. My view of the shared responsibility for a good-quality text of a published scientific paper is presented in the subsections below.

\subsection{The author's responsibility}

At the beginning of this section I would like to quote a sentence from "Elements of style" [1] which sums up my views on the primary responsibility of the author:

\section{"If the research is worth writing up, it's worth writing up well."}

The author's responsibility is not only the quality of the presented achievement, breakthrough, or development in his field of expertise, but also the quality of the text. A good text implies the proper register (formal academic writing), adequate terminology (technical vocabulary) and special terminology related to academic writing (sub-technical terminology), as well as a good structure, cohesion and coherence. Therefore, the author should put additional effort into communicating the research results in a proper way.

The heavy load of responsibility for both the scientific contribution and its presentation in the paper is not easy for the author to bear, but it is lightened if the author knows for sure that he/she cannot be accused of negligence. We all know that a human error exists and that designers have to include safety margins in their designs to compensate for potential human errors. Therefore, some mistakes in the text can be accepted as inevitable, but there is no excuse for negligence, such as: 


\section{- Ungrammatical sentences - e.g.}

When the fire extinguished, austenite phase of NiTinol spring change to martensite phase and returns back to its initial position.

Corrected sentence (the changes are highlighted):

When the fire is extinguished, the austenite phase of NiTinol spring changes to the martensite phase and the spring returns to its initial position.

- Incomplete sentences - e.g.

Although much work has been done in EDM of materials and optimizing EDM condition.

- Inconsistency - e.g. using both decimal points and decimal commas in the same table, graph or diagram; or using different terms for the same concept, such as green water, shipping of water, shipping water, shipped water and deck wetness for the concept of "A large quantity of water on a ship's deck as a result of massive waves during a large storm".

- Inaccuracy - e.g. using a non-existent term the angle of the contact angle of gear teeth or using the gerund meshing in plural, e.g. in such meshings of gears. The plural is not a lapsus calami type of a mistake because the same form occurs several times in the paper. It is difficult to find an excuse for these mistakes since the author could have checked the terminology ina dictionary, a handbook, or on the internet.

- Carelessness in making the suggested changes - For example, the author accepts the changes made by the language editor but does not look for the remaining mistakes of the same type and does not correct them, as suggested by the language editor.

True, the majority of authors try to do their best to produce the best possible version of the paper, but, due to tight deadlines or the lack of skill, some scientific papers are not written up to the high quality level of their scientific contribution. The authors are not to be blamed for that as they are under constant pressure of the well-known "publish or perish" culture that has invaded the academic world. In addition, most of the authors have not been trained in writing. But, the writing skill can be improved by writing, rewriting, and learning from one's mistakes. Therefore, good cooperation with the language editor is suggested because it is important in two ways: first, the author can learn from his mistakes made obvious by the language editor; second, if the author checks thoroughly the language editor's corrections and/or suggestions, he/she also makes sure that the text transfers the right, intended content from the point of view of the field of expertise.

\subsection{The peer reviewer's responsibility}

The peer reviewer's full responsibility for evaluating the quality of the scientific contribution presented in the paper is a generally accepted fact. However, I believe that the peer reviewer should also be responsible for the quality of the text in which the scientific research is presented. In this respect, the peer reviewer is primarily responsible for the correct terminology as he/she is an expert in the field and the right person to identify and/or solve a problem. The problem may be a wrong scientific term but also the usage of different scientific terms denoting the same phenomenon. These problems should be identified and solutions should be suggested by the peer reviewer:

If the peer reviewer has a problem with reading the text and has to refer to his expert knowledge to understand the text, then he/she should insist that the language be improved. 
But a common phrase "the language should be improved" is very vague and unfortunately not very helpful. If the language is really bad, the peer reviewer should insist on sending the paper back to the author(s) to rewrite it, supporting his decision by concrete examples. Thus, the peer reviewer should, for example, state that the term "special technique parts" is not an acceptable term for the intended concept (parts of military equipment and vehicles, as previously stated).

The fact is that the role of a peer reviewer is anything but easy because he/she should be an expert in the field, should have an excellent command of English, and should act as a technical editor. And, we all know that his task is very time-consuming. That is why all the authors should be grateful to peer-reviewers for their work.

\subsection{The editor's responsibility}

At the beginning of this section, let me quote Leslie Sage, Senior Editor in Nature, who said in the introduction to his seminar "How to publish in Nature":

"The writing should be clear, concise and directed at the level of a graduate course in the subject. I encourage authors to contact me in advance of submission of a paper, both to ascertain the appropriateness of the result for Nature, and to ensure that the writing is close to our standards.“

This quotation illustrates the fact that editors of scientific journals accept the responsibility for the quality of the paper both in terms of its scientific contribution and of good scientific writing. Moreover, "Elements of Style" [1] and "Writing a clear and engaging paper for all astronomers" [9], two very useful texts about good scientific writing written by experts in different fields of science with experience as editors of Nature, prove that the editors want to share their insights into good scientific writing with prospective authors. In addition, these texts show that the editors take on an active role in the creation of a good quality scientific text.

Another thing that I would like to point out from the above quotation is the question of standards of a journal. I think that it is the editor's and the editorial board's responsibility to set standards and to make sure that they are maintained. The world's leading science journals, such as Nature, have very rigorous quality standards that cannot be adopted by every science journal, but I believe that every science journal should establish adequate quality standards to be met and can even improve them in time. If there are no standards, poor scientific writing becomes acceptable.

\subsection{The language editor's responsibility}

The language editor must always be aware of $t$ role in the creation of the best possible version of a text. First, he/she is NOT the author and should always respect the author and his style. Also, in most instances, he/she is not an expert in the scientific field the paper deals with. Therefore, close cooperation with the author in an attempt to improve the text is required, especially with reference to terminology or sentence structure. All the changes made to the text by the language editor have to be visible so that the author can accept or reject them. As mentioned before, the final responsibility for the text lies with the author.

On the other hand, the language editor has responsibility towards the reader and towards his field of expertise, i.e. the language and the text. Bearing the reader in mind, the language editor has to make sure the text can be understood by a non-expert reader and has to act accordingly, hoping that the author will accept his suggestions. Correcting spelling mistakes and grammatical errors is within the range of language expertise and it usually does not pose problems if the reviewer is familiar with the scientific field of the paper. Changing sentence 
structure is also within the range of expertise of the language editor but here there is a possibility of misinterpretation of the scientific content and of committing serious mistakes with respect to the scientific content. To avoid that possibility, such changes may be done only if approved by the author of the text.

The third point to be considered again is human error. True, the skill and expertise are prerequisites for good language editing, but they do not suffice unless they are accompanied by the undivided attention. This means that the language editor has to be fully dedicated to the task of correcting mistakes. It is not always easy to spot each and every mistake as attention may be distracted or diverted. Generally, this problem can be efficiently solved by rereading the text several times. Thus, I spotted the mistake in the expression "the slop of the location" only in the third reading when I realized that an " $\mathrm{e}$ " is missing at the end of the word (the slope). In the previous two readings of the text, I was too busy solving other problems in the text so that my eye saw what I expected to see and not what was actually written. This mistake is not of major importance as the reader who is a non-native speaker of English would hardly notice it, but the native speaker would laugh at it (slop = waste water from a kitchen, bathroom, or chamber pot that has to be emptied by hand).

The second and the third reading of the text take the language editor deeper into the text, beyond the level of accuracy to the level of precise meaning, better style, and simpler solutions. Here, the language editor specialized in particular fields of engineering may find solutions to the problems spotted in grammatically correct sentences. The following two examples show that a dedicated language editor with basic expert knowledge can spot a mistake at the level of the information to be conveyed and can suggest the right solution after having read the text with due attention paid to all its aspects.

Example 11 - original sentence:

The magnitude of the cantilever solid triangle at the free end is $51 \mathrm{~N} / \mathrm{mm}^{2}$.

In the first reading I just highlighted the sentence as I realized that the unit $\mathrm{N} / \mathrm{mm}^{2}$ could not refer to the noun triangle and that an appropriate noun (stress, for example) should be inserted. In the second reading, I checked the unit to confirm my guess and wrote a comment to the authors suggesting to fill in the missing noun. The authors made the necessary changes.

Example 12 - original sentence:

All specimens quenched with subsequent DCT showed a contraction after the first tempering and full dimensional stability after the first tempering.

The problem in this sentence is that both the contraction and the dimensional stability were achieved after the first tempering, which is not logical as the conjunction "and" expresses contrast. Obviously, the dimensional stability was achieved after the second tempering.

Example 13 - original sentence:

Wheel diameter coated with a rubber layer was $222 \mathrm{~mm}$ and its rotation speed was $200 \mathrm{rpm}$.

At first sight, this sentence is an example of a grammatically correct sentence. On the other hand, if you analyse the meaning, then you realize that it is not the "wheel diameter" that is coated with rubber nor does it (the diameter) rotate at a "rotation speed" (the original term quoted here is not accurate as we are talking about rotational speed). In the end, this sentence has proved to be a challenge that can be responded to only by an attentive and focused reader/language editor. The corrected form of the sentence proposed to the author is as follows: 
The diameter of the wheel coated with a rubber layer was $222 \mathrm{~mm}$; the rotational speed was $200 \mathrm{rpm}$.

In conclusion, close cooperation between the language editor and the author of the scientific paper should be pointed out once again. The language editor corrects the language and suggests changes with the best intentions of improving the quality of the text. Good cooperation with the author in terms of discussing the proposed changes and explaining the problematic parts is very rewarding for both parties involved, and the final result is a goodquality text. The lack of cooperation on the part of the author makes the life of a language editor miserable. After having corrected the language and written some comments using the Track Changes tool, the language editor is very disappointed and demotivated when he/she receives the corrected version of the paper sent back without any comments or answers to the questions. Checking the problematic parts of the text and comparing it with the version with comments and questions is very time-consuming and frustrating, and the final version of the text might still have problematic parts unresolved.

\section{CONCLUSIONS}

I hope that this paper has managed to raise the awareness of how important a goodquality text is in the presentation of a scientific achievement because it is written for that purpose. I believe that all the parties involved in the process of writing and publishing a paper do share the responsibility for the quality of the text, but without any doubt, the primary responsibility lies with the author(s). The section two which deals with scientific writing and the section three which deals with the author's responsibility are dedicated to the present and future authors. The aim is to suggest practical guidelines for writing better/the best possible scientific papers. As the author, I have also tried to follow all these guidelines; it is up to the reader to judge how successful I have been in doing so. What I know is that I am certainly living proof that writing is hard.

The issues discussed in this paper are those that have proven to be obstacles to communicating the right message or to presenting the scientific achievement in a way that it deserves. Therefore, I would like to sum up the most important experience-based recommendations for good scientific writing presented in the paper:

- The title of the paper is very important. It should be specific enough, possibly with the results included, but also not too technical for a non-expert reader. And, it should not be too long. Quite a challenge, which requires time, effort, and attention focused to the reader.

- Each section of the paper has its role, so authors should try to make sure that the function of the section is fulfilled.

- The text should be written in good English that a non-expert reader can understand. Sentences should be well-structured and not too long, while the wording should be simple but precise.

- Mistakes that inhibit understanding should be avoided at all costs.

- Proper terminology should be used consistently. If there are several terms used for the same concept, one term should be selected and used throughout the text.

- Literal translation into English of the terms used in the author's mother tongue should be avoided as this is usually a bad practice resulting in the dissemination 
of wrong terminology. Instead, the terminology should be checked with reliable sources.

- The over-use of initialism should be avoided as they distract the reader's attention. The best solution is to use only the ones that are common in a particular field of expertise. The use of newly created initialisms is justified in tables and graphs, but one has to make sure that they are introduced properly in the captions.

- Special attention should be paid to spelling. Spelling mistakes can indicate the author's carelessness and a lack of respect for his paper in the first place and also for the reader and the journal in which the paper is published.

As I have used quotations at the beginning of two sections, perhaps it might be a good idea to conclude this paper with another quotation, that of Aristophanes:

"By words, the mind is winged".

I believe that this saying is true even when it comes to good scientific writing. And I am neither the first nor the only one to come to the same conclusion; in 1990, Gopen and Swan stated that improving the quality of writing actually improves the quality of thought [4]. And the quality of thought is what makes the difference.

\section{REFERENCES}

[1] Nature Publishing Group (2007), "Elements of Style”, Editorial, Nature Physics, Vol. 3, No. 9.

[2] Alley, M., The Craft of Scientific Writing, $3^{\text {rd }}$ edition, Springer-Verlag, 1996, DOI:10.1007/978-1-4757-2482-0..

[3] Bednar, J. A. "Tips for Academic Writing and Other Formal Writing" http://homepages.inf.ed.ac.uk/jbednar/writingtips (Retrieved: 22 May 2015).

[4] Gopen, G., Swan, J. (1990), “The Science of Scientific Writing”, American Scientist, NovemberDecember issue (Retrieved: 10 August 2015 from http://www.americanscientist.org/issues/feature/thescience-of-scientific-writing).

[5] Doumont, J., ed., (2010): English Communication for Scientists (Unit 2 - Writing scientific papers), Cambridge, MA: NPG Education. http://www.nature.com/scitable/ebooks/english-communication-forscientists-14053993/writing-scientific-papers-14239285 (Retrieved: 14 August 2015).

[6] Strunk Jr., W. and White, E. B. (2000): The Elements of Style, Fourth Edition, Pearson, Boston, Columbus, Indianapolis, New York, San Francisco, etc.

[7] Tokić, B. (2004) "Jesu li “jezik u struci” i "nazivlje u struci” istoznačni pojmovi?" (There is more to English for science and technology than the field-related terminology), Proceedings of XVI Symposium SORTA 2004, Plitvička jezera. FSB, Zagreb, topic 12, paper 3.

[8] Biber, D., Johansson, S., Leech, G., Conrad, S., and Finegan. E. (1999): Grammar of spoken and written English, Longman.

[9] Sage, L. (2003), "Writing a clear and engaging paper for all astronomers", in Astronomy Communication, editors: Heck, A., Madsen, C., Series volume 290, pp 221-226, DOI:10.1007/978-94-017-0801-2_13.

[10] Zemach, D. E., Rumisek, L. A. (2005): Academic Writing: from paragraph to essay, $3^{\text {rd }}$ edition, Oxford, Macmillan.

[11] Halliday, M., Hasan, R., (1976): Cohesion in English, Longman, London.

[12] Carter, R., McCarthy, M. (2006): Cambridge Grammar of English, Cambridge University Press, Cambridge, New York, Melbourne, Madrid, Cape Town, Singapore, São Paulos.

[13] Merriam-Webster online dictionary http://www.merriam-webster.com/dictionary/.

[14] Macmillan Dictionary http://www.macmillandictionary.com/dictionary/_(Retrieved: 28 June 2015).

[15] Fara, V., (2004) English as a global lingua franca, Strani jezici 33 (2004), 3-4, pp 309-321.

[16] Kereković, S., (2014): Primjena terminoloških načela na sinonimne tehničke nazive (The application of terminological principles to synonymous engineering terms), Polimeri, 35 (2014) 1-2:18-24. 
[17] Oxford Advanced Learner's Dictionary (1995), Fifth edition ( $2^{\text {nd }}$ impression), Oxford University Press, Oxford, New York.

[18] The Free Dictionary of Acronyms by Farlex http://acronyms.thefreedictionary.com/CNC (Retrieved: 9 July 2015).

[19] Crystal, D. (2006): "The Fight for English - 1", Lingua Franca Blog www.davidcrystal.com/?field=4060 (Retrieved: 7 April 2017).

[20] Kohl, J. R. (2008): The Global English Style Guide: Writing Clear, Translatable Documentation for a Global Market, SAS Institute.

[21] Sage, L.: Introduction to seminar "How to Publish in Nature" http://www.astro.puc.cl:8080/astropuc/seminars/how-to-publish-a-paper-in-nature-lesliesage? set_language $=$ en (Retrieved: 11 August 2015).

Submitted: $\quad 06.6 .2016$

Accepted: $\quad 17.10 .2016$
Božena Tokić, MSc, Senior Lecturer in retirement

bozena.tokic@fsb.hr 